\title{
Sperm-carried RNAs play critical roles in mouse embryonic development
}

\author{
Lei Guo ${ }^{1, *}$, Shi-Bin Chao ${ }^{2,3, *}$, Lu Xiao ${ }^{4}$, Zhen-Bo Wang ${ }^{2,5}$, Tie-Gang Meng ${ }^{2,4}$, Yuan- \\ Yuan Li ${ }^{2}$, Zhi-Ming Han², Ying-Chun Ouyang ${ }^{2}$, Yi Hou' ${ }^{2}$, Qing-Yuan Sun ${ }^{2,5}$ and Xiang- \\ Hong Ou ${ }^{1}$ \\ ${ }^{1}$ Center for Reproductive Medicine, Guangdong Second Provincial General Hospital, Guangzhou 510317, PR China \\ ${ }^{2}$ State Key Laboratory of Stem Cell and Reproductive Biology, Institute of Zoology, Chinese Academy of Sciences, Beijing \\ 100101, PR China \\ ${ }^{3}$ The ART Center, Jiujiang Maternal and Child Health Care Hospital, Jiangxi 332000, PR China \\ ${ }^{4}$ Department of Obstetrics and Gynecology, Nanfang Hospital, Southern Medical University, Guangzhou 510515, PR China \\ ${ }^{5}$ College of Life Sciences, University of Chinese Academy of Sciences, Beijing 100049, PR China \\ * These authors have contributed equally to this work \\ Correspondence to: Xiang-Hong Ou, email: ouxianghong2003@163.com \\ Qing-Yuan Sun, email: sunqy@ioz.ac.cn \\ Keywords: sperm RNA, RNase, intracytoplasmic sperm injection, blastocyst formation, offspring \\ Received: March 28, $2017 \quad$ Accepted: May 22, $2017 \quad$ Published: June 27, 2017 \\ Copyright: Guo et al. This is an open-access article distributed under the terms of the Creative Commons Attribution License 3.0 \\ (CC BY 3.0), which permits unrestricted use, distribution, and reproduction in any medium, provided the original author and source \\ are credited.
}

\section{ABSTRACT}

Recently, numerous studies have reported that the mature sperm contains both coding and non-coding RNAs and the sperm delivers some RNAs to the oocyte at fertilization. However, the functions of the RNAs carried to the oocyte by sperm at fertilization in embryonic development remains a mystery. In this study, the mature spermatozoa were treated with lysolecithin, pronase and RNases (RNase A and RNase $H)$ to remove the sperm-carried RNAs, and then injected into normal mature oocyte. The results showed that after the treatment, the content of the sperm RNAs was decreased by about $90 \%$. The blastocyst formation rate and the live birth rate of the embryos from intracytoplasmic sperm injection (ICSI) using the treated sperm were significantly decreased $(P<0.01)$, while these effects were partially rescued by injecting total wide-type sperm RNAs. The reproductive capacity of offspring (FO) in sperm-treated group was similar with that in control group $(P>0.05)$, but the body weight of F1 mice from sperm-treated group was lower than that in control group after two weeks of birth $(P<0.05)$. These results demonstrated that the sperm-carried RNAs have important roles in embryonic development.

\section{INTRODUCTION}

Meiosis is a series of nuclear and cytoplasmic events that produce a haploid gamete which has the capability to complete fertilization and then establish an embryo. The maturing oocyte undergoes a series of dynamic morphological and nuclear rearrangements, during which its transcriptional activity sharply decreases, but oocyte accumulates maternal RNAs that will ensure early stages of embryogenesis until zygotic genome activation [1]. The production of mature male gametes is also a complex process. Spermatogonia differentiate to primary spermatocytes, then though meiosis, the round spermatids are formed [2]. At the final step of spermiogenesis, the majority of the cytoplasm with most RNAs is depleted; meanwhile the nuclear histones are replaced by protamines. Finally, the sperm becomes a highly differentiated transcriptionally inactive specialized cell containing minimal cytoplasm and compacted nucleus [3].

In classical concept, almost all the necessary cytoplasmic components for early embryonic development are from oocyte, and the only contribution of sperm is 
paternal genomic DNA. Recently, numerous studies have reported the existence of sperm RNA in mammals, including rat [4], mouse [5], and human [6, 7]. Ostermeier et al. found that a human sperm RNA profile contains about 3000-7000 types of coding transcripts using microarrays [8]. Nextgeneration sequencing technique provides a more complete picture of transcript population in mature spermatozoa, including both known and unknown transcripts [9, 10]. RNA-seq analysis showed that the mature sperm contains both coding and non-coding RNAs that include both fragmented and non-degraded mRNAs, siRNAs, miRNAs, piRNAs and long non-coding RNAs [11].

There is no doubt that the sperm delivers some RNAs to the oocyte at fertilization. The individual functions of some transcripts in mature sperm have been elucidated $[12,13]$, but the functions of the RNAs carried to the oocyte by sperm at fertilization in embryonic development remains a mystery. In this study, the mature spermatozoa were treated with lysolecithin (LL), pronase (P) and RNases (RNase A and RNase $\mathrm{H}$ ) to remove the sperm-carried RNAs, and then injected into normal mature oocytes to observe the functions of sperm RNAs in embryo development. The blastocyst formation and the offspring were detected.

\section{RESULTS}

\section{Sperm RNAs after $\mathbf{L}+\mathbf{P}+\mathbf{R N a s e s}$ treatment}

To remove RNAs, the spermatozoa were treated with lysolecithin, pronase and RNases (RNase A and RNase H). After the treatment, the content of sperm RNAs was decreased by about $90 \% \quad(53.64 \pm 10.67$ $\left.\mathrm{ng} / 10^{7} \mathrm{VS} 538.88 \pm 34.16 \mathrm{ng} / 10^{7}\right)$. To detect whether all RNAs were reduced, RNA-seq was performed. A total of 35565 transcripts were obtained from RNAseq. Compared to control group, the contents of 20083 transcripts were lower, and 14225 transcripts were not detected in treated group (Figure 1A and Figure 1B). The gene ontology analysis found that $44.95 \%, 16.41 \%$ and $38.64 \%$ of the transcripts encoding proteins were related to the biological process, molecular function and cellular component, respectively (Figure 1C). In the biological process, 3893 transcripts were involved in development process and 922 were related to reproductive process, including 6 mRNAs encoding proteins associated with embryonic cleavage (GO: 0040016), 30 with blastocyst formation (GO:0001825), 61 with blastocyst development (GO:0001824) and 21 with blastocyst growth (GO:0001832) (Table 1).

\section{Oocytes fertilized by ICSI using spermatozoa treated with $L L+P+R$ Nases display reduced developmental potential}

To test whether sperm with low RNA contents could support fertilization and early embryonic development, we respectively injected the control sperm and the sperm treated with $\mathrm{LL}+\mathrm{P}+\mathrm{RNases}$ into oocytes $(\mathrm{C} 57 \mathrm{BL} / 6 \mathrm{~J})$, and counted the number of embryos at each preimplantation developmental stage to evaluate the developmental potential. The blastocyst formation rate of embryos from treated sperm was significantly reduced, compared to the control group $(P<0.01)$ (Table 2$)$. To evaluate the postimplantation development of the embryos derived from treated sperm, two-cell embryos were transferred into the oviducts of recipient mice to observe the development to term. The live birth rate of embryos in the control group was significantly higher than that in the treated group (36.67\% VS 3.21\%, $P<0.01$ ) (Table 3), suggesting that the developmental potential of embryos derived from ICSI using RNA-deficient spermatozoa was decraesed.

\section{Supplementation of wide-type (WT) sperm RNAs significantly improves the blastocyst formation rate and the birth rate of ICSI embryos derived from the treated sperm}

The reduced developmental potential of embryos derived from ICSI using $\mathrm{LL}+\mathrm{P}+\mathrm{RNases}$-treated sperm might not be due to the deficiency in RNA contents because these sperm underwent a series of treatment in vitro. To test whether supplementation of total normal paternal RNAs improves the developmental potential of the embryos, total RNAs isolated from WT sperm were injected into oocyte fertilized by sperm treated with LL+P+RNases through ICSI. After injected total WT sperm RNAs, the blastocyst formation rate of embryos from ICSI with $\mathrm{LL}+\mathrm{P}+\mathrm{RNases}$-treated sperm was significantly increased than that of the embryos from $\mathrm{LL}+\mathrm{P}+\mathrm{RNases}$-treated sperm through ICSI without injection of WT sperm RNAs $(P<0.01)$ (Table 2). To examine the post-implantation development of the embryos from treated spermatozoa and injected total WT sperm RNAs, 2-cell embryos were transferred into the oviducts of recipient mice. $19.77 \%$ of 2-cell transferred embryos from treated spermatozoa and injected with total WT sperm RNAs led to live-born pups, significantly higher than that of the embryos derived from treated spermatozoa without injected total WT sperm RNAs $(P<0.01)$ (Table 3$)$. This suggested that supplementation of normal sperm-carried RNAs can partially rescue not only the preimplantation development, but also the birth rate of ICSI embryos from RNA-deficient sperm in mice.

\section{Expression patterns of H3K27me3, H3K4me3, H3K14ac and H4K12ac in late 1-cell and 2-cell embryos from $\mathbf{L}+\mathbf{P}+\mathbf{R N a s e s - t r e a t e d ~ s p e r m ~ a r e ~}$ normal}

As an important part of epigenetics, histone modifications play important roles in maintaining higher-order chromatin structure and in regulating various chromatin processes, such as DNA repair, DNA 
replication and transcription during development [14]. To detect whether histone modifications are affected by an initial lack of sperm-carried RNAs during the zygotic genome activation, the expression patterns of $\mathrm{H} 3 \mathrm{~K} 4 \mathrm{me} 3$, $\mathrm{H} 3 \mathrm{~K} 27 \mathrm{me} 3$, H3K14ac and H4K12ac in late 1-cell and 2-cell embryos from ICSI using $\mathrm{LL}+\mathrm{P}+\mathrm{RNases}$-treated spermatozoa were examined. Immunofluorescence staining showed that H3K4me3, H3K27me3, H3K14ac and H4K12ac were expressed in both male and female pronuclei of late 1-cell embryos and in each nucleus of 2-cell embryos from control group or LL+P+RNasestreated sperm group (Figure 2 and Figure 3). No discernable differences were observed between the two groups.

\section{Effects of RNA deficiency in sperm on offspring}

The offspring (F0) from ICSI using LL+P+RNasestreated sperm with or without supplementation of WT sperm RNAs could develop to adulthood normally. To test the effects of RNA-deficient sperm in offspring, the

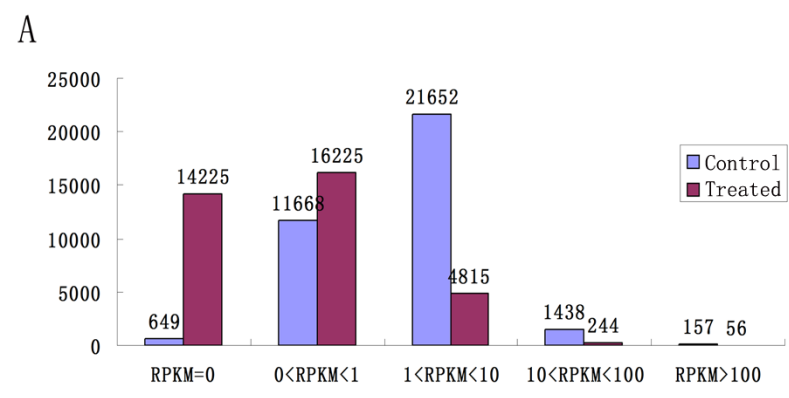

B

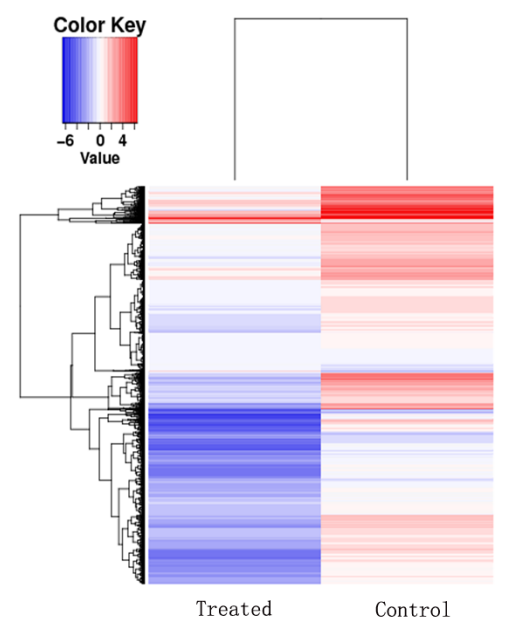

C

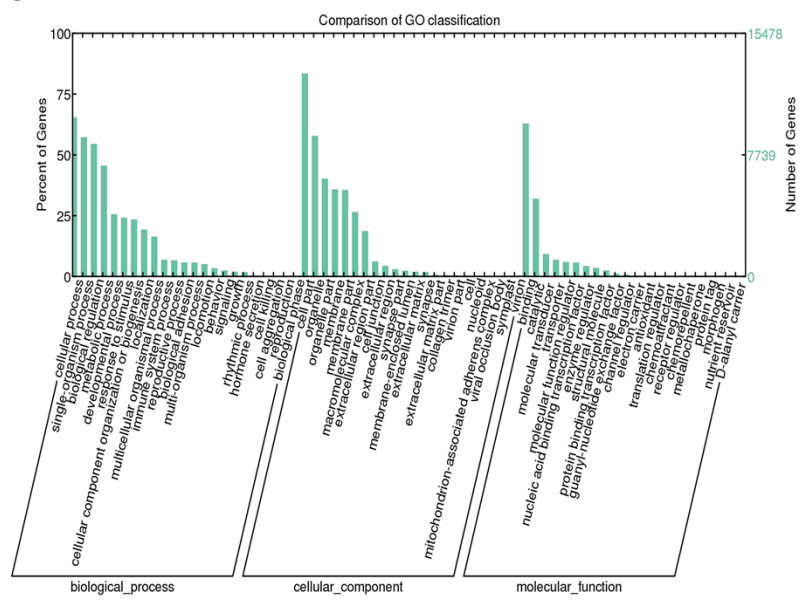

Figure 1: Analysis of RNA-seq data from the sperm with or without LL+P+RNases-treatment. (A) Distribution of RPKM from the sperm with or without treatment. (B) Heat maps derived from cluster analysis of RNA-seq from the sperm with or without treatment. (C) The gene ontology analysis of the differentially expressed RNAs from the sperm with or without treatment. 
Table 1: The ontological categories of different expressive transcripts associated with embryonic cleavage, blastocyst formation, blastocyst development and blastocyst growth

\begin{tabular}{|c|c|c|c|}
\hline GO term & Description & No. of genes & Genes \\
\hline GO:0040016 & $\begin{array}{c}\text { embryonic } \\
\text { cleavage }\end{array}$ & 6 & $\begin{array}{l}\text { Cullin-3, Protein AATF, DNA topoisomerase 2-alpha, } \\
\text { Phosphatidylinositol 4,5-bisphosphate 3-kinase catalytic subunit beta isoform, } \\
\text { DNA topoisomerase 1, TFIIH basal transcription factor complex helicase } \\
\text { XPD subunit }\end{array}$ \\
\hline GO:0001825 & $\begin{array}{l}\text { blastocyst } \\
\text { formation }\end{array}$ & 30 & $\begin{array}{l}14 \text { kDa phosphohistidine phosphatase, Adenosine deaminase, B-cell } \\
\text { lymphoma/leukemia 10, Butyrophilin subfamily } 2 \text { member A2, Butyrophilin- } \\
\text { like protein 2, C-C chemokine receptor type 7, CKLF-like MARVEL } \\
\text { transmembrane domain-containing protein 3, CMRF35-like molecule } 8 \text {, } \\
\text { Dual specificity protein phosphatase 22, E3 ubiquitin-protein ligase CBL-B, } \\
\text { ETS-related transcription factor Elf-1, Fc receptor-like protein 5, Germinal } \\
\text { center-associated signaling and motility protein, Intermediate conductance } \\
\text { calcium-activated potassium channel protein 4, Leupaxin, Mucosa-associated } \\
\text { lymphoid tissue lymphoma translocation protein } 1 \text { homolog, NFAT activation } \\
\text { molecule 1, Protein TESPA1, Receptor-type tyrosine-protein phosphatase C, } \\
\text { Roquin-1, Serine/threonine-protein kinase D2, Signal-transducing adaptor } \\
\text { protein 1, Thy-1 membrane glycoprotein, Transcription factor Sp1, Tyrosine- } \\
\text { protein kinase Lyn, Tyrosine-protein phosphatase non-receptor type } 2 \text {, } \\
\text { Tyrosine-protein phosphatase non-receptor type } 6 \text {, Ubiquitin-associated and } \\
\text { SH3 domain-containing protein A, Voltage-dependent L-type calcium channel } \\
\text { subunit alpha-1F, Zona pellucida sperm-binding protein } 3\end{array}$ \\
\hline GO:0001824 & $\begin{array}{c}\text { blastocyst } \\
\text { development }\end{array}$ & 61 & 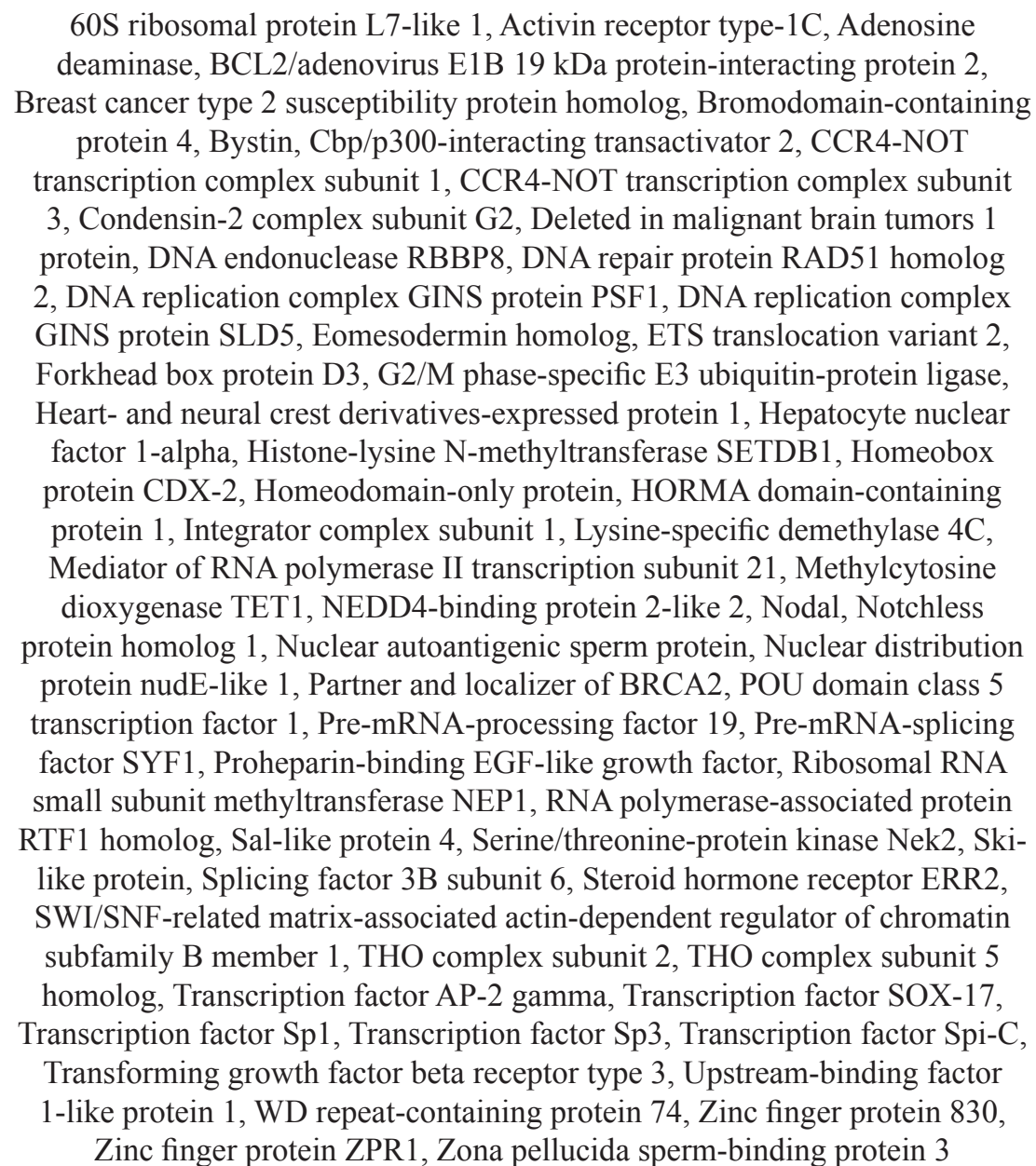 \\
\hline
\end{tabular}

(Continued) 


\begin{tabular}{|c|c|c|c|}
\hline GO term & Description & No. of genes & Genes \\
\hline GO:0001832 & $\begin{array}{l}\text { blastocyst } \\
\text { growth }\end{array}$ & 21 & $\begin{array}{l}\text { Activin receptor type-1C, Breast cancer type } 2 \text { susceptibility protein homolog, } \\
\text { Bromodomain-containing protein 4, Condensin-2 complex subunit G2, } \\
\text { Deleted in malignant brain tumors } 1 \text { protein, DNA repair protein RAD51 } \\
\text { homolog 2, DNA replication complex GINS protein PSF1, DNA replication } \\
\text { complex GINS protein SLD5, Histone-lysine N-methyltransferase SETDB1, } \\
\text { Integrator complex subunit 1, Nuclear distribution protein nudE-like 1, } \\
\text { Partner and localizer of BRCA2, POU domain class } 5 \text { transcription factor } \\
\text { 1, Pre-mRNA-processing factor 19, Proheparin-binding EGF-like growth } \\
\text { factor, RNA polymerase-associated protein RTF1 homolog, Sal-like protein } \\
\text { 4, Steroid hormone receptor ERR2, Upstream-binding factor 1-like protein 1, } \\
\text { Zinc finger protein 830, Zinc finger protein ZPR1 }\end{array}$ \\
\hline
\end{tabular}

Table 2: Preimplantation development of embryos derived from ICSI using WT oocytes and LL+P+RNases-treated sperm with or without total WT sperm RNA

\begin{tabular}{|c|c|c|c|c|c|c|}
\hline & \multirow[b]{2}{*}{ No. of oocytes injected } & \multicolumn{5}{|c|}{ Number of embryos at each stage } \\
\hline & & $\begin{array}{c}2 \mathrm{PN} \\
\text { (\% of total) }\end{array}$ & $\begin{array}{c}2 \text {-cell } \\
(\% \text { of } 2 \mathrm{PN})\end{array}$ & $\begin{array}{l}4-8 \text {-cell } \\
\text { (\% of } \\
2 \text {-cell) }\end{array}$ & $\begin{array}{c}\text { Morula } \\
\text { (\% of } \\
\text { 2-cell) }\end{array}$ & $\begin{array}{l}\text { Blastocyst } \\
\text { (\% of 2-cell) }\end{array}$ \\
\hline Control & 156 & $151(96.79)$ & $125(82.78)$ & $116(92.80)$ & $102(81.60)$ & $70(56.00)$ \\
\hline $\mathrm{LL}+\mathrm{P}+\mathrm{RNases}$-treated & 227 & $218(96.04)$ & $177(81.19)$ & $161(90.96)$ & $139(78.53)$ & $28(15.82)^{* *}, \# \#$ \\
\hline $\begin{array}{l}\text { LL+P+RNases-treated + } \\
\text { WT sperm RNA }\end{array}$ & 82 & $77(93.9)$ & $67(87.01)$ & $61(91.04)$ & $56(83.58)$ & $27(40.30)$ \\
\hline
\end{tabular}

${ }^{* *} \mathrm{LL}+\mathrm{P}+\mathrm{RNases}$-treated group VS control group, $P<0.01$.

\# LL+P+RNases-treated + WT sperm RNA group VS LL+P+RNase-treated group, $P<0.01$.

Table 3: Term development of mouse embryos developed from the oocytes fertilized by injection of LL+P+RNasestreated sperm with or without total WT sperm RNA

\begin{tabular}{lcc}
\hline & $\begin{array}{c}\text { No. of 2-cell embryos transferred } \\
\text { (No. of recipients) }\end{array}$ & No. of live offspring at term (\%) \\
\hline Control & $60(4)$ & $22(36.67)$ \\
LL+P+RNases-treated & $187(10)$ & $6(3.21)^{* *, \# \#}$ \\
LL+P+RNases-treated + WT sperm RNA & $86(5)$ & $17(19.77)$ \\
\hline
\end{tabular}

${ }^{* *} \mathrm{LL}+\mathrm{P}+\mathrm{RNases}$-treated group VS control group, $P<0.01$.

\#LL+P+RNases-treated + WT sperm RNA group VS LL+P+RNase-treated group, $P<0.01$.

reproductive capacity of offspring (F0) and the body weight trajectories of offspring (F1) were detected. The results showed that the reproductive capacity of F0 females or males in treated group was similar to that in control group $(P>0.05)$ (Table 4). However, the body weight of $\mathrm{F} 1$ mice from sperm-treated group was lower than that in control group after two weeks of birth $(P<0.05)$ (Figure 4).

\section{DISCUSSION}

In this study, we demonstrate that the content of the sperm RNAs was decreased by about $90 \%$ after treatment with $\mathrm{LL}+\mathrm{P}+\mathrm{RNases}$, and that the blastocyst formation rate and the live birth rate were significantly decreased in embryos derived from ICSI using $\mathrm{LL}+\mathrm{P}+\mathrm{RNases}-$ treated sperm, compared to control 
A

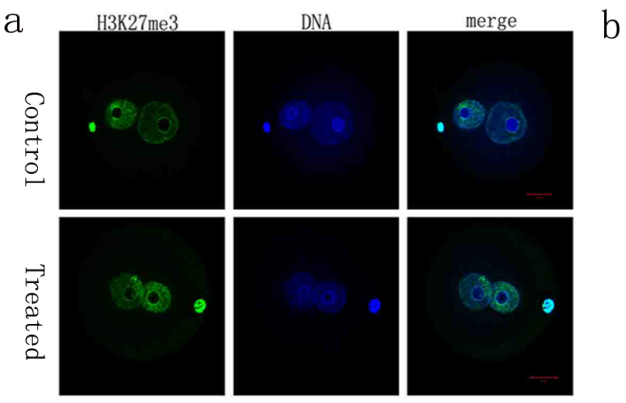

b

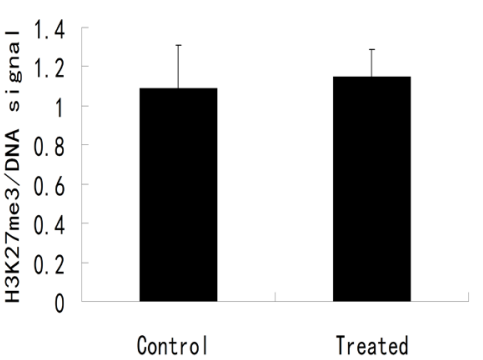

$\mathrm{B}$
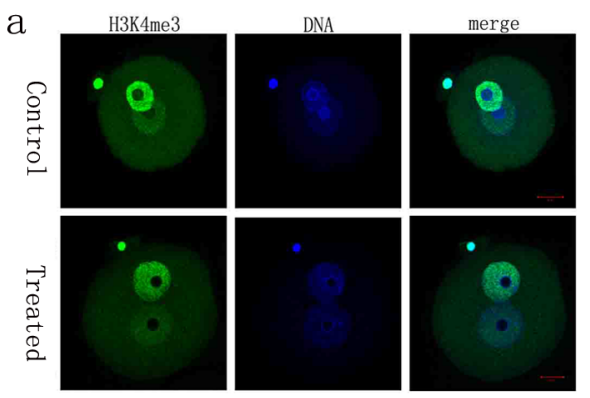

$\mathrm{b}$
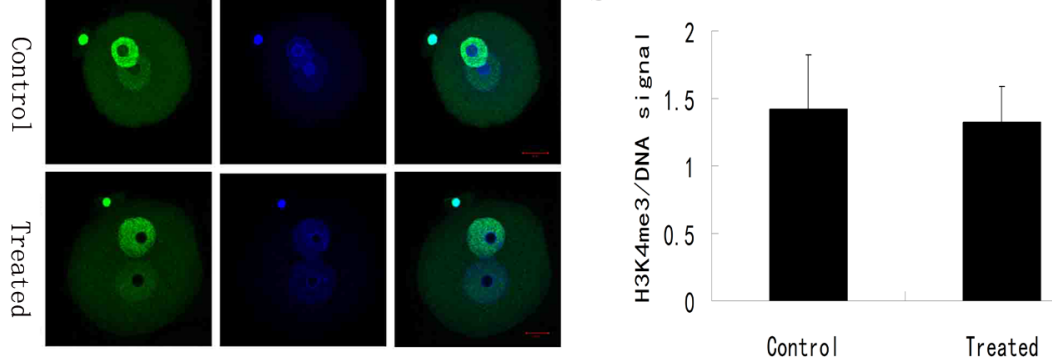

C
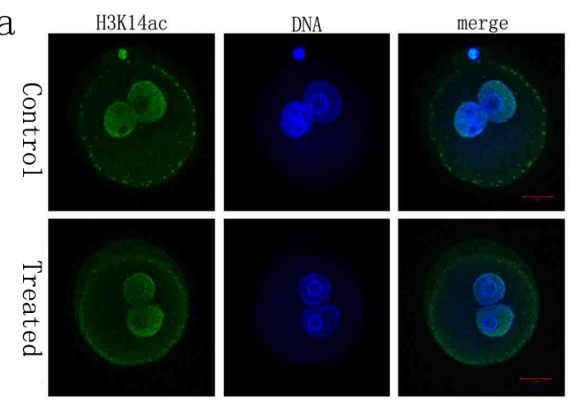

$\mathrm{b}$

D
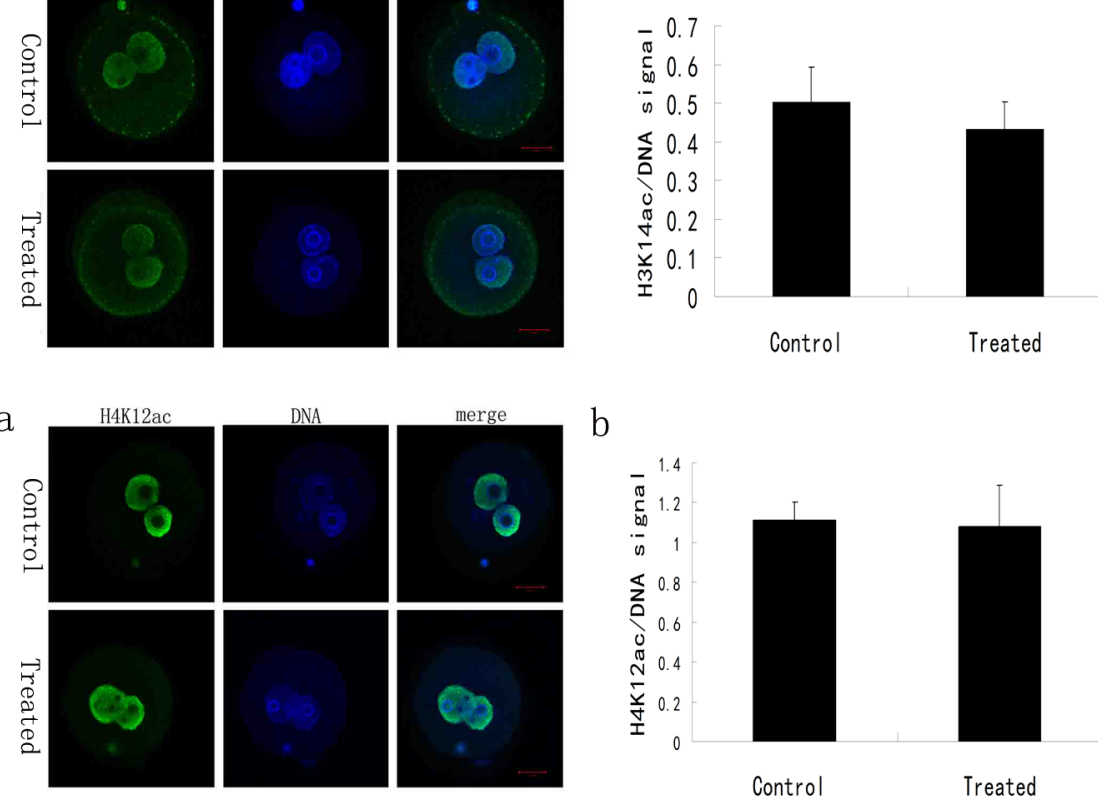

$\mathrm{b}$

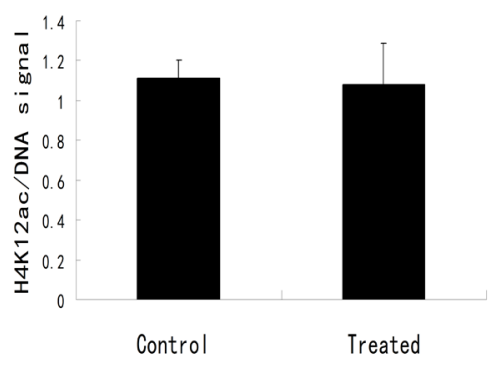

Figure 2: Histone modifications of the late 1-cell stage embryos derived from ICSI using the sperm with or without LL+P+RNases-treatment. (A) H3K27me3 in the late 1-cell stage embryos derived from ICSI using the sperm with or without treatment $(\mathrm{n}=18)$. The staining pattern of H3K27me3 in the late 1-cell stage embryos derived from ICSI using the sperm with or without treatment (a) and the ratio of $\mathrm{H} 3 \mathrm{~K} 27 \mathrm{me} / \mathrm{DNA}$ signal intensity in the late 1-cell stage embryos derived from ICSI using the sperm with or without treatment (b). H3K27me3: green; DNA: blue. Bar=20 $\mu \mathrm{m}$. (B) H3K4me3 in the late 1-cell stage embryos derived from ICSI using the sperm with or without treatment $(n=20)$. The staining pattern of H3K4me3 in the late 1-cell stage embryos derived from ICSI using the sperm with or without treatment (a) and the ratio of H3K4me3/DNA signal intensity in the late 1-cell stage embryos derived from ICSI using the sperm with or without treatment (b). H3K4me3: green; DNA: blue. Bar=20 $\mu \mathrm{m}$. (C) H3K14ac in the late 1-cell stage embryos derived from ICSI using the sperm with or without treatment $(n=19)$. The staining pattern of H3K14ac in the late 1-cell stage embryos derived from ICSI using the sperm with or without treatment (a) and the ratio of H3K14ac/DNA signal intensity in the late 1-cell stage embryos derived

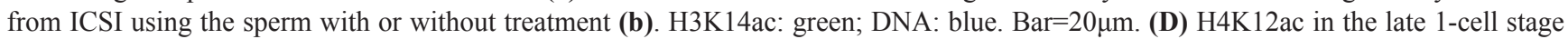
embryos derived from ICSI using the sperm with or without treatment $(n=18)$. The staining pattern of H4K12ac in the late 1-cell stage embryos derived from ICSI using the sperm with or without treatment (a) and the ratio of H4K12ac/DNA signal intensity in the late 1-cell stage embryos derived from ICSI using the sperm with or without treatment (b). H4K12ac: green; DNA: blue. Bar=20 $\mu$ m. 
A
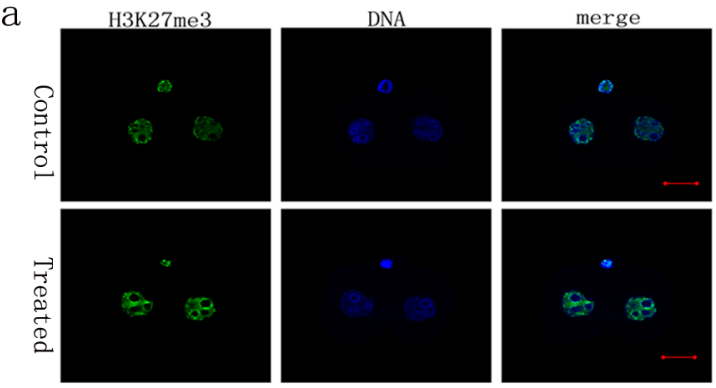

B

a
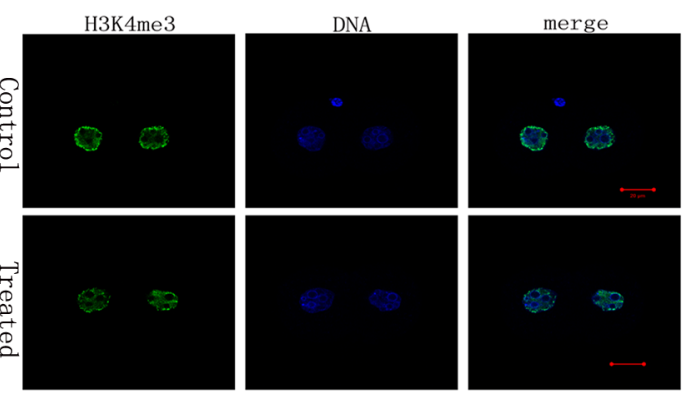

C

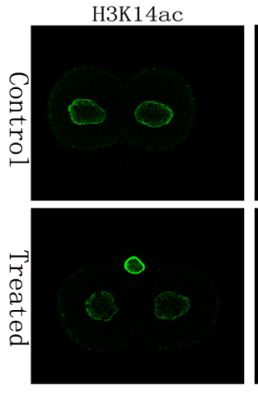

D
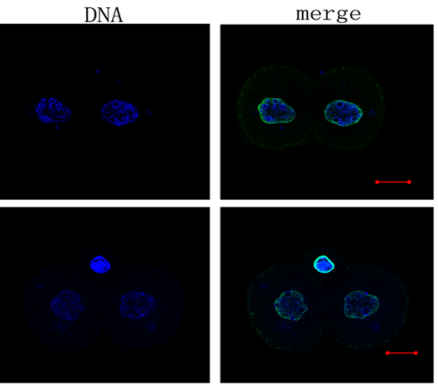

a

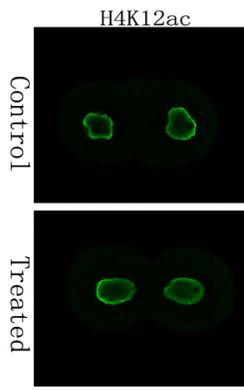

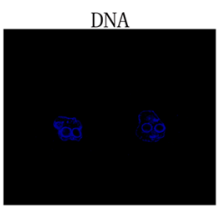

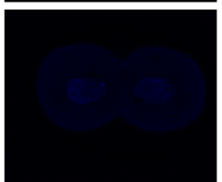

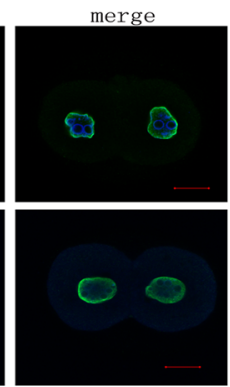

b

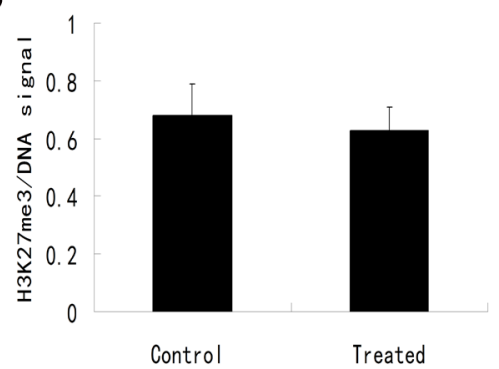

b

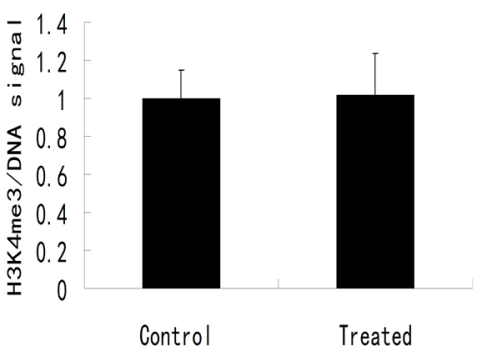

b

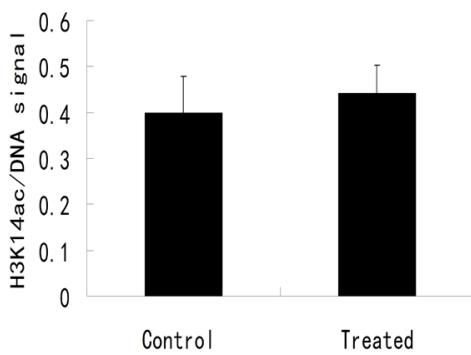

b

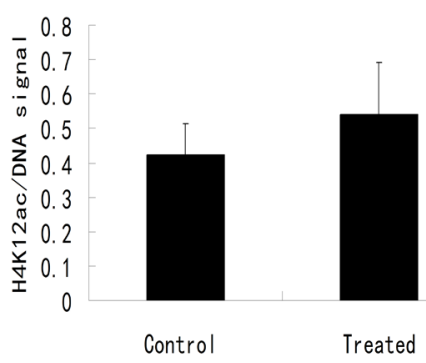

Figure 3: Histone modifications of the 2-cell stage embryos derived from ICSI using the sperm with or without LL+P+RNases-treatment. (A) H3K27me3 in 2-cell stage embryos derived from ICSI using the sperm with or without treatment (n =20). The staining pattern of H3K27me3 in 2-cell stage embryos derived from ICSI using the sperm with or without treatment (a) and the ratio of H3K27me3/DNA signal intensity in 2-cell stage embryos derived from ICSI using the sperm with or without treatment (b). H3K27me3: green; DNA: blue. Bar $=20 \mu \mathrm{m}$. (B) H3K4me3 in 2-cell stage embryos derived from ICSI using the sperm with or without treatment $(\mathrm{n}=18)$. The staining pattern of $\mathrm{H} 3 \mathrm{~K} 4 \mathrm{me} 3$ in 2-cell stage embryos derived from ICSI using the sperm with or without treatment (a) and the ratio of $\mathrm{H} 3 \mathrm{~K} 4 \mathrm{me} 3 / \mathrm{DNA}$ signal intensity in 2-cell stage embryos derived from ICSI using the sperm with or without treatment

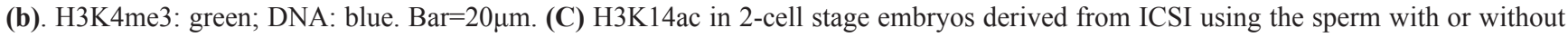
treatment $(n=21)$. The staining pattern of H3K14ac in 2-cell stage embryos derived from ICSI using the sperm with or without treatment (a) and th ratio of H3K14ac/DNA signal intensity in 2-cell stage embryos derived from ICSI using the sperm with or without treatment

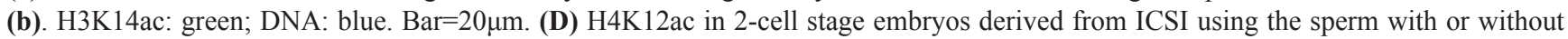
treatment $(n=17)$. The staining pattern of H4K12ac in 2-cell stage embryos derived from ICSI using the sperm with or without treatment (a) and the ratio of H4K12ac/DNA signal intensity in 2-cell stage embryos derived from ICSI using the sperm with or without treatment (b). H4K12ac: green; DNA: blue. Bar=20 $\mu \mathrm{m}$. 
Table 4: The reproductive capacity of F0 mice

\begin{tabular}{llccc}
\hline & & No. of mice examined & No. of total litters & No. of offspring per litter \\
\hline Female & control & 3 & 19 & $8.21 \pm 0.37$ \\
& LL+P+RNases-treated & 3 & 18 & $7.72 \pm 0.38$ \\
\multirow{2}{*}{ Male } & control & 3 & 20 & $8.11 \pm 0.21$ \\
& LL+P+RNases-treated & 3 & 18 & $7.89 \pm 0.43$ \\
\hline
\end{tabular}

group. The offspring from ICSI using LL+P+RNasestreated spermatozoa could develop to adulthood normally, and the reproductive capacity of offspring (F0) was similar to that in the control group, but the body weight of F1 mice was lower than that in control group after two weeks of birth.

In the late 1990s, various studies reported the presence of different types of RNAs in mammalian spermatozoa [11]. The spermatozoal RNAs include both fragmented and non-degraded mRNAs, siRNAs, miRNAs, piRNAs and long non-coding RNAs [11]. A much more complete picture of transcript population in mature spermatozoa could be provided using a new next-generation sequencing technique. Approximately 22302 unique transcripts were detected using RNA-seq in human mature sperm [9]. In mouse, RNA-seq showed that the mature sperm had more than 33000 different transcripts, including 27310 coding transcripts [15]. In situ hybridization (ISH) studies on spermatozoa have found that RNAs are localized in the entire head region [16], and some ISH data show that the midpiece of sperm tail is another site of RNA deposition [17]. Lysolecithin and pronase were used to remove the acrosomal and plasma membrane and some perinuclear materials [18]. RNase A cleaves nucleoside 3'-phosphates and 3'-phosphooligonucleotides ending in $\mathrm{Cp}$ or Up in single-stranded RNA [19], and the activity of RNase $\mathrm{H}$ is the cleavage of RNA in RNA/DNA hybrids [19]. In this study, to remove the sperm RNAs, we treated the mouse mature sperm with lysolecithin and pronase, and then further treated with RNase A and RNase $\mathrm{H}$. The results showed that after treatment, the content of sperm RNAs was reduced by about $90 \%$. Furthermore, RNA-seq analysis showed that 20083 of 35565 transcripts were lower, and 14224 transcripts were not detected in $\mathrm{LL}+\mathrm{P}+\mathrm{RNases}$-treated sperm, compared with control group. This might because that RNases did not get to the location of some RNAs or the enzyme activity was inhibited to some extent in the sperm nucleus, leading to removal failure of a small fraction of RNAs.

A

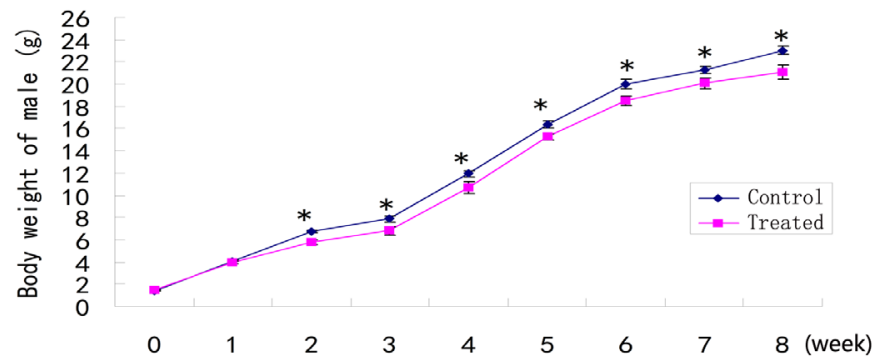

B

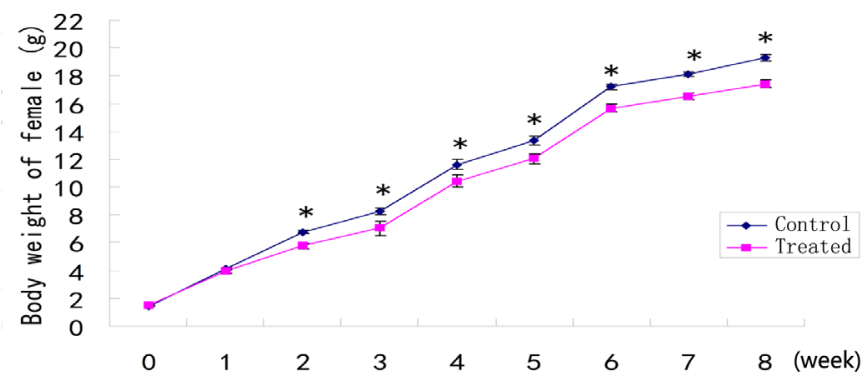

Figure 4: The body weight trajectories of F1 males (A) and females (B). ${ }^{*} P<0.05$. 
There is no doubt that the sperm delivers some RNAs to the oocyte at fertilization. Three different types of sperm RNAs have been discovered [20]. The first group of RNAs has an important function during spermatogenesis but has no role in post-fertilization events. The presence of this set of RNAs could be used as a diagnostic tool to detect the quality of mature spermatozoa [12, 21, 22]. A second group of RNAs from a non-testicular source can be introduced into the oocyte during fertilization by sperm $[23,24]$. The third group of RNAs from the testicular germ cells may have roles in the fertilized egg. Sperm-specific Plc $\zeta \mathrm{mRNA}$ injected into the mouse oocyte translated into $\mathrm{PLC} \zeta$ protein and induced functional calcium oscillations [25]. Yao et al reported that spermborne Dby mRNA regulated the zygotic development after Dby mRNA transferred into pronucleus [26]. Meanwhile, some noncoding RNAs in mature spermatozoa might have functions in early embryo development. Injection of miR-34c inhibitor into zygotes inhibits first cleavage division, suggesting that miR-34c has important role in the first cleavage division in mice [27], but the miR-34b/c knockout mice displayed normal fertility [13]. Previous study found that the live birth rate from the oocyte through ICSI using sperm treated with lysolecithin was increased [28], and the rate of live-born normal offspring, using sperm treated with lysolecithin and pronase, was decreased [18]. Pronase treatment may remove some peinuclear materials or some RNAs which play implant roles in embryonic development [18]. In this study, we treated the mature sperm with $\mathrm{LL}+\mathrm{P}+\mathrm{RNases}$ to remove the sperm RNAs, and then injected the treated sperm into oocyte. The blastocyst formation rate and the live birth rate of the embryo from treated sperm were significantly decreased than that in control group $(P<0.01)$. When we injected the total WT sperm RNAs into eggs, the blastocyst formation rate and the live birth rate of the embryo from treated sperm were increased, suggesting that total sperm RNAs could rescue the decreased developmental potential of embryo from treated sperm. These results show that deletion of sperm RNAs reduces the blastocyst formation rate and thus the live birth rate.

Sperm-specific RNAs may be epigenetic modifiers to affect the phenotype of the offspring. Microinjection of total RNAs from Kit ${ }^{\text {tm1Alf/t }}$ mouse into fertilized eggs induced white tail in offspring [29]. Increasing evidences indicate that metabolic disorders in offspring are due to the father's diet. Fasting of male mice before mating with female mice decreased serum glucose level in offspring [30] and the high-fat diet of male rats affected pancreatic islet biology in offspring [31]. The offspring from the normal zygotes injected with the total sperm RNAs or tRNAs from the male mice given a high-fat diet developed impaired glucose tolerance, showing higher blood glucose and serum insulin levels [32]. Moreover, differentially expressed sperm tsRNAs between control and high-fat diet males preferentially match to some gene promoter regions by sequence matches analysis, and biological pathway analysis showed that these matched genes are associated with diverse cellular and molecular processes, including apoptosis, autophagy, oxidative stress, glucose input (such as Maea, Ccnc and Deptor regulates the pancreatic $\beta$-cell function) [32]. In this study, RNases not only delete mRNAs, but also tRNAs. After the treatment with RNases, some sperm tRNAs, which affect genes involved in metabolism, may decrease, so the body weight of F1 mice from the treated sperm was lower than that from the control group.

In conclusion, the blastocyst formation rate and the live birth rate were decreased in embryos from ICSI using RNA-deficient sperm, and the body weight of F1 mice from the RNA-deficient sperm was lower than that from the control group. These results suggest that the sperm RNAs play critical roles in embryonic development.

\section{MATERIALS AND METHODS}

All chemicals and media were purchased from Sigma Chemical Company (St. Louis, MO) except for those specifically mentioned.

\section{Animals}

C57BL/6 mice were used to collect oocyte and sperm or to reproduce. Female mice mated with CD-1 vasectomized males were used as embryo recipients. Mice care and handling abided to the Animal Research Committee guidelines of the Institute of Zoology, Chinese Academy of Sciences.

\section{Preparation of spermatozoa}

Cauda epididymal spermatozoa were dispersed into $\mathrm{HTF}$ medium. After incubation for $1 \mathrm{~h}$ at $37^{\circ} \mathrm{C}$ in a $\mathrm{CO}_{2}$ incubator, the spermatozoa were washed once with HTF medium by centrifugation. Sperm pellets were resuspended in a medium consisting of $250 \mathrm{mM} \mathrm{NaCl}, 100 \mathrm{mM}$ Tris$\mathrm{HCl}, 10 \mathrm{mM}$ EGTA, $0.2 \%(\mathrm{w} / \mathrm{v})$ lysolecithin, and $0.1 \%$ $(\mathrm{w} / \mathrm{v})$ pronase $(\mathrm{PH} 7.8)$ and incubated at $37^{\circ} \mathrm{C}$ for $0.5 \mathrm{~h}$ [18], then the sperm were treated with $5 \mathrm{mg} / \mathrm{ml}$ RNase A (TAKARA) and $400 \mathrm{U} / \mathrm{ml}$ RNase $\mathrm{H}$ (TAKARA) at $37^{\circ} \mathrm{C}$ for $1.5 \mathrm{~h}$, followed by centrifugation. To remove the RNases, the pellets were washed six times in 500 $\mu 1$ Hepes$\mathrm{CZB}$ with each time for 2 mins, and then centrifugated $1 \mathrm{~min}$ using 1000rpm. The spermatozoa were used for RNA isolation, or intracytoplasmic sperm injection (ICSI).

\section{RNA isolation and RNA-seq}

The total sperm RNAs were extracted using TRIzol reagent (Invitrogen) following the manufacturer's instructions including DNase treatment (Ambion). RNA was evaluated with a NanoDrop 6000 Labchip kit 
(Nanodrop) and an Agilent 2100 Bioanalyzer (Agilent Technologies, Santa Clara, CA, USA). Then the RNA was subjected to RNA sequencing following manufacturer's recommendations (Novogene) using Illumina Hiseq 2500 instrument (Illumina, San Diego, CA, USA). Data collection and analysis was performed as previously described [33-35].

\section{Intracytoplasmic sperm injection (ICSI) and embryo culture}

Intracytoplasmic sperm injection was carried out as described [36, 37]. $5 \mu \mathrm{l}$ sperm suspension was mixed with $10 \mu \mathrm{l}$ Hepes-CZB containing $10 \%$ (w/v) polyvinylpyrrolidone. A drop of this mixture was transferred into a plastic dish under paraffin oil previously placed on the objective table of an inverted microscope equipped with a Piezo-drill micromanipulation system. Two types of spermatozoa were injected into oocytes: 1) an intact sperm after washing with HTF medium, as control; 2) a sperm head after treatment with $L L+P+R N a s e s$ and washing with Hepes-CZB. The treated spermatozoa were used in $1 \mathrm{~h}$ after treatment. For rescuing the reduction of sperm RNA, 1-2pl total sperm RNA (0.1 ng/ $\mu \mathrm{l})$ was injected into an oocyte before the treated sperm was injected. After ICSI, the oocytes were activated by $\mathrm{Ca}^{2+}$ free $\mathrm{CZB}$ containing $5 \mathrm{mM} \mathrm{SrCl}_{2}$ for $30 \mathrm{~min}$, then cultured in $\mathrm{KSOM}^{\mathrm{AA}}$ (Millipore) at $37^{\circ} \mathrm{C}$ in a $\mathrm{CO}_{2}$ incubator.

\section{Immunofluorescence and confocal microscopy}

The process of immunoflurescence was performed as previously described $[14,38]$. After fixed with $4 \%$ paraformaldehyde for $30 \mathrm{~min}$ and permeabilized for 30 min with $0.2 \%$ Triton X-100 in PBS and blocked in a blocking solution (1\% BSA and $0.05 \%$ Tween-20 in PBS) for $2 \mathrm{~h}$ at room temperature, the embryos cultured $11 \mathrm{~h}$ after ICSI or at 2-cell stage were then incubated with antibodies to $\mathrm{H} 3 \mathrm{~K} 27 \mathrm{me} 3$ (Abcom), H3K4me3 (Epigentek), H3k14ac (Upstate) or H4k12ac (Upstate) overnight at $4^{\circ} \mathrm{C}$. The samples were washed three times with washing buffer (PBS supplemented with $0.1 \%$ Tween 20 and $0.01 \%$ Triton X-100). Then the embryos were incubated with a fluorescein isothiocyanate (FITC)conjugated goat anti-rabbit antibody (Zhong Shan Jin Qiao) for $1 \mathrm{~h}$ at room temperature. Following three washes in washing buffer, DNA was stained with Hoechst 33342 $(10 \mathrm{mg} / \mathrm{ml})$, and all samples were mounted in antifade solution. The embryos were observed on a Zeiss LSM 780 microscope (Carl Zeiss). The embryos of the same developmental stage were photographed used the same instrument parameters. Nuclear intensities of integrated fluorescence were measured with the ImageJ $1.44 \mathrm{p}$ software as previously described [39]. All individual nuclei in embryos need outlined manually. After background subtraction, total fluorescence intensities of all individual nuclei in each embryo were obtained. The ratios of the fluorescence intensity of $\mathrm{H} 3 \mathrm{~K} 27 \mathrm{me} 3$, H3K4me3, H3k14ac or H4k12ac to Hoechst 33342 DNA signal in the same embryo from ICSI using the sperm with or without $\mathrm{LL}+\mathrm{P}+\mathrm{RNases}$-treated were compared. The images were managed using the Adobe Photoshop software (Adobe Systems, San Jose, CA) and no contrast or brightness were adjusted.

\section{Embryos transfer}

Two-cell embryos were transferred into oviducts of CD-1 pseudopregnant females mated with vasectomized males at the previous night.

\section{Evaluation of reproductive capacity of offspring (F0) from the treated sperm}

To evaluate the reproductive capacity, three female and three male offspring (F0) from the LL+P+RNasestreated sperm group or control group at the age of 8 week were mated with wide type C57BL/6 male or female mice, respectively. The numbers of pups and litters were recorded up to 6 months.

\section{Evaluation of body weight trajectories of offspring (F1) from the treated sperm}

To examine the body weight trajectories, the F1 offspring in six litters from the LL+P+RNases-treated sperm group (F0) or control group (F0) were weighed every week for 8 weeks, respectively.

\section{Statistical analyses}

Data were expressed as mean \pm sem. Statistical differences between datasets were assessed by Student's $t$-test or $c h i$-squared test with the IBM SPSS Statistics 19.0 software. A value of $P<0.05$ was considered statistically significant.

\section{ACKNOWLEDGMENTS}

We are grateful to Shi-Wen Li, Li-Juan Wang, and Hua Qin for technical assistance.

\section{CONFLICTS OF INTEREST}

The authors have no conflicts of interest to disclose.

\section{FUNDING}

This work was supported by the National Natural Science Foundation of China (Grant No. 31301185 and 81671425 ) and a grant from Ministry of Science and Technology of China (2016YFA0100400). 


\section{REFERENCES}

1. Sirard MA. Factors affecting oocyte and embryo transcriptomes. Reprod Domest Anim. 2012; 47:148-155.

2. Hess RA, Renato de Franca L. Spermatogenesis and cycle of the seminiferous epithelium. Adv Exp Med Biol. 2008; 636:1-15.

3. Lalancette C, Miller D, Li Y, Krawetz SA. Paternal contributions: new functional insights for spermatozoal RNA. J Cell Biochem. 2008; 104:1570-1579.

4. Pessot CA, Brito M, Figueroa J, Concha, II, Yanez A, Burzio LO. Presence of RNA in the sperm nucleus. Biochem Biophys Res Commun. 1989; 158:272-278.

5. Wykes SM, Miller D, Krawetz SA. Mammalian spermatozoal mRNAs: tools for the functional analysis of male gametes. J Submicrosc Cytol Pathol. 2000; 32:77-81.

6. Kumar G, Patel D, Naz RK. c-MYC mRNA is present in human sperm cells. Cell Mol Biol Res. 1993; 39:111-117.

7. Wykes SM, Visscher DW, Krawetz SA. Haploid transcripts persist in mature human spermatozoa. Mol Hum Reprod. 1997; 3:15-19.

8. Ostermeier GC, Dix DJ, Miller D, Khatri P, Krawetz SA. Spermatozoal RNA profiles of normal fertile men. Lancet. 2002; 360:772-777.

9. Sendler E, Johnson GD, Mao S, Goodrich RJ, Diamond MP, Hauser R, Krawetz SA. Stability, delivery and functions of human sperm RNAs at fertilization. Nucleic Acids Res. 2013; 41:4104-4117.

10. Krawetz SA, Kruger A, Lalancette C, Tagett R, Anton E, Draghici S, Diamond MP. A survey of small RNAs in human sperm. Hum Reprod. 2011; 26:3401-3412.

11. Jodar M, Selvaraju S, Sendler E, Diamond MP, Krawetz $\mathrm{SA}$. The presence, role and clinical use of spermatozoal RNAs. Hum Reprod Update. 2013; 19:604-624.

12. Cho C, Jung-Ha H, Willis WD, Goulding EH, Stein P, Xu Z, Schultz RM, Hecht NB, Eddy EM. Protamine 2 deficiency leads to sperm DNA damage and embryo death in mice. Biol Reprod. 2003; 69:211-217.

13. Yuan S, Tang C, Zhang Y, Wu J, Bao J, Zheng H, Xu C, Yan W. mir-34b/c and mir-449a/b/c are required for spermatogenesis, but not for the first cleavage division in mice. Biol Open. 2015; 4:212-223.

14. Guo L, Qi ST, Miao DQ, Liang XW, Li H, Ou XH, Huang X, Yang CR, Ouyang YC, Hou Y, Sun QY, Han Z. The roles of parathyroid hormone-like hormone during mouse preimplantation embryonic development. PLoS One. 2012; 7:e40528.

15. Fang $\mathrm{P}$, Zeng $\mathrm{P}$, Wang Z, Liu M, Xu W, Dai J, Zhao X, Zhang D, Liang D, Chen X, Shi S, Zhang M, Wang L, et al. Estimated diversity of messenger RNAs in each murine spermatozoa and their potential function during early zygotic development. Biol Reprod. 2014; 90:94.
16. Dadoune JP, Alfonsi MF, Fain-Maurel MA. Cytochemical variations in the nucleolus during spermiogenesis in man and monkey. Cell Tissue Res. 1991; 264:167-173.

17. Modi D, Shah C, Sachdeva G, Gadkar S, Bhartiya D, Puri C. Ontogeny and cellular localization of SRY transcripts in the human testes and its detection in spermatozoa. Reproduction. 2005; 130:603-613.

18. Yan W, Morozumi K, Zhang J, Ro S, Park C, Yanagimachi R. Birth of mice after intracytoplasmic injection of single purified sperm nuclei and detection of messenger RNAs and MicroRNAs in the sperm nuclei. Biol Reprod. 2008; 78:896-902.

19. Rittie L, Perbal B. Enzymes used in molecular biology: a useful guide. J Cell Commun Signal. 2008; 2:25-45.

20. Boerke A, Dieleman SJ, Gadella BM. A possible role for sperm RNA in early embryo development. Theriogenology. 2007; 68:S147-155.

21. Carrell DT, Liu L. Altered protamine 2 expression is uncommon in donors of known fertility, but common among men with poor fertilizing capacity, and may reflect other abnormalities of spermiogenesis. J Androl. 2001; 22:604-610.

22. Cho C, Willis WD, Goulding EH, Jung-Ha H, Choi YC, Hecht NB, Eddy EM. Haploinsufficiency of protamine-1 or -2 causes infertility in mice. Nat Genet. 2001; 28:82-86.

23. Smith K, Spadafora C. Sperm-mediated gene transfer: applications and implications. Bioessays. 2005; 27:551-562.

24. Lavitrano M, Busnelli M, Cerrito MG, Giovannoni R, Manzini S, Vargiolu A. Sperm-mediated gene transfer. Reprod Fertil Dev. 2006; 18:19-23.

25. Sone $\mathrm{Y}$, Ito $\mathrm{M}$, Shirakawa $\mathrm{H}$, Shikano T, Takeuchi H, Kinoshita K, Miyazaki S. Nuclear translocation of phospholipase C-zeta, an egg-activating factor, during early embryonic development. Biochem Biophys Res Commun. 2005; 330:690-694.

26. Yao CJ, Xu WJ, Gong XL, Zhou Y, Yan ZQ, Zhu ZJ, Wang ZX, Li QL, Guo XB, Wang LY, Ma D, Qiao ZD. The role of Dby mRNA in early development of male mouse zygotes. Asian J Androl. 2010; 12:567-577.

27. Liu WM, Pang RT, Chiu PC, Wong BP, Lao K, Lee KF, Yeung WS. Sperm-borne microRNA-34c is required for the first cleavage division in mouse. Proc Natl Acad Sci U S A. 2012; 109:490-494.

28. Morozumi K, Shikano T, Miyazaki S, Yanagimachi R. Simultaneous removal of sperm plasma membrane and acrosome before intracytoplasmic sperm injection improves oocyte activation/embryonic development. Proc Natl Acad Sci U S A. 2006; 103:17661-17666.

29. Rassoulzadegan M, Grandjean V, Gounon P, Vincent S, Gillot I, Cuzin F. RNA-mediated non-mendelian inheritance of an epigenetic change in the mouse. Nature. 2006; 441:469-474. 
30. Anderson LM, Riffle L, Wilson R, Travlos GS, Lubomirski MS, Alvord WG. Preconceptional fasting of fathers alters serum glucose in offspring of mice. Nutrition. 2006; 22:327-331.

31. Ng SF, Lin RC, Laybutt DR, Barres R, Owens JA, Morris MJ. Chronic high-fat diet in fathers programs betacell dysfunction in female rat offspring. Nature. 2010; 467:963-966.

32. Chen Q, Yan M, Cao Z, Li X, Zhang Y, Shi J, Feng GH, Peng H, Zhang X, Qian J, Duan E, Zhai Q, Zhou Q. Sperm tsRNAs contribute to intergenerational inheritance of an acquired metabolic disorder. Science. 2016; 351:397-400.

33. Wang L, Feng Z, Wang X, Zhang X. DEGseq: an R package for identifying differentially expressed genes from RNAseq data. Bioinformatics. 2010; 26:136-138.

34. Wagner GP, Kin K, Lynch VJ. Measurement of mRNA abundance using RNA-seq data: RPKM measure is inconsistent among samples. Theory Biosci. 2012; 131:281-285.
35. Gan H, Wen L, Liao S, Lin X, Ma T, Liu J, Song CX, Wang M, He C, Han C, Tang F. Dynamics of 5-hydroxymethylcytosine during mouse spermatogenesis. Nat Commun. 2013; 4:1995.

36. Kimura Y, Yanagimachi R. Intracytoplasmic sperm injection in the mouse. Biol Reprod. 1995; 52:709-720.

37. Chao SB, Guo L, Ou XH, Luo SM, Wang ZB, Schatten H, Gao GL, Sun QY. Heated spermatozoa: effects on embryonic development and epigenetics. Hum Reprod. 2012; 27:1016-1024.

38. Guo L, Wang ZB, Wang HH, Zhang T, Qi ST, Ouyang YC, Hou Y, Sun QY. Nek11 regulates asymmetric cell division during mouse oocyte meiotic maturation. Biochem Biophys Res Commun. 2016; 474:667-672.

39. Shi LH, Ai JS, Ouyang YC, Huang JC, Lei ZL, Wang Q, Yin S, Han ZM, Sun QY, Chen DY. Trichostatin A and nuclear reprogramming of cloned rabbit embryos. J Anim Sci. 2008; 86:1106-1113. 